\title{
Phylogenetic relationships among four species of the guarani group of Drosophila (Diptera, Drosophilidae) as inferred by molecular and morphological analyses
}

\author{
Lizandra Jaqueline Robe ${ }^{1}$ \\ Luciano Basso da Silva ${ }^{2}$ \\ Elgion Lucio da Silva Loreto ${ }^{1}$
}

\begin{abstract}
Traditionally, the Drosophila guarani species group has been divided into two subgroups: the guarani and the guaramunu subgroups. Two, out of the four species included in this research, are members of the guarani subgroup (D. ornatifrons Duda, 1927 and D. subbadia Paterson \& Mainland, 1943) and two are included in the guaramunu subgroup (D. maculifrons Duda, 1927 and D. griseolineata Duda, 1927). However, some authors have suggested that D. maculifrons and D. griseolineata are much closer to some species of the Drosophila tripunctata group than to some of the species of the guarani group. To add new data to the matter under dispute, Polyacrylamide Gel Eletrophoresis (PAGE-SDS) was used for the analysis and comparison of protein composition and Random Amplified Polymorphic DNA (RAPD) analysis to find differences in genomic DNA, in addition to the analysis of quantitative morphological characters previously described. Analysis of PAGE-SDS results in a dendrogram that pointed out D. subbadia as being the most distant within the Drosophila guarani group. However, these results were not supported either by RAPD analysis or by the analysis of continuous morphological characters, which supplied the clustering of D. subbadia with D. ornatifrons. Although our data give strong support to the clustering of D. subbadia and D. ornatifrons, none of the dendrograms provided a clade comprising $D$. maculifrons and $D$. griseolineata. Thus, this research does not support the traditional subdivision of the $D$. guarani group into those two subgroups.
\end{abstract}

KEYwORDs: Drosophila; guarani group; monophyly; phylogeny; RAPD.

\section{INTRODUCTION}

The genus Drosophila is famous for its contribution to genetic research. The evolutionary biology of this genus has, on the same way, been extensively studied, with morphological (ThrocKMORTON 1975; GrimALDI 1990) and molecular studies (DeSAlle 1992; KwiatowsKi \& Ayala 1999) having decisively contributed to the establishment of the phylogenetic relationships between various species of this genus. Nevertheless, many gaps in our knowledge and disagreements between different workers on specific points occur (O’GRADY \& Kidwell 2002).

This divergence between authors can be illustrated by the controversy between workers regarding the phylogeny of the Drosophila guarani group. This group is traditionaly placed in the Drosophila quinaria section of THROCKMORTON's (1962) phylogeny but in a branch comprising Drosophila tripunctata, D. cardini, D. calloptera and D. quinaria in MALOGOLOWKIN's (1953) phylogeny, as has been discussed by VAL et al. (1981). THROCKMORTON (1975) regarded the guarani group as originating from $D$. tripunctata radiation.

At present the guarani group is made up of a total of 12 species (VILELA \& PEREIRA 1985, 1993), all very abundant in the Neotropical region (VAL et al. 1981). Morphological data (THROCKMORTON 1975) point to the division of the guarani group into two subgroups: the guaramunu subgroup, which includes D. guaraja King, 1947, D. maculifrons Duda, 1927 (=D. guaramunu according to VILELA \& Bächli 1990) and D. griseolineata Duda, 1927; and the guarani subgroup containing D. ornatifrons Duda, 1927 (=D. guarani according to VILELA \& BäCHLI 1990) and D. subbadia Paterson \& Mainland, 1943 (VAL et al. 1981). However, KASTRITSIS (1969)

\footnotetext{
1. Departamento de Biologia, Universidade Federal de Santa Maria - UFSM. 97105-900 Santa Maria - RS, Brazil.

E-mail: elgion@base.ufsm.br

2. Pós-Graduação em Genética e Biologia Molecular, Universidade Federal do Rio Grande do Sul - UFRGS. Porto Alegre - RS, Brazil.
} 
states that $D$. maculifrons and $D$. griseolineata are closer to some members of the tripunctata group than to some species of the guarani group and suggests that the guaramunu and the guarani subgroups should be raised to the status of species groups.

Because of this divergence between authors and the absence of molecular data supporting any of these results, we decided to undertake new studies to propose new hypotheses regarding the relationships between the members of the group. Of the 12 Drosophila species included in the guarani group, four were chosen to take part of this research:D. maculifrons, $D$. griseolineata, D. ornatifrons and D. subbadia. These taxa were investigated for polymorphisms that might allow the elaboration of a phylogeny. Protein composition was studied using Polyacrylamide Gel Electrophoresis (PAGE-SDS) while Random Amplified Polymorphic DNA (RAPD) analysis of total DNA was used to detect genomic differences. Some previously described morphological quantitative characters (VILELA \& BäCHLI 1990) were also included in the analysis.

\section{MATERIAL AND METHODS}

\section{Drosophila stocks}

A stock of D. maculifrons was established from individual specimens collected in São Marcos district of Santa Maria, Rio Grande do Sul, Brazil.D. ornatifrons and D. griseolineata were collected at Morro Santana, Porto Alegre, Rio Grande do Sul, Brazil. A stock of D. subbadia was obtained from the Bowling Green Stock Center (BGSC, Bowling Green, Ohio, USA, now at Tucson, Arizona, USA), stock number 15172-2161.1, collected in El Naranjo, Mexico. The outgroup species, D. melanogaster Harwich strain, was also obtained from the BGSC.

\section{Genomic DNA and proteins extraction}

Protein for PAGE-SDS was extracted according to the protocol described by WALKER (1986), about 5 flies being used per $100 \mathrm{ml}$ of buffer because above this PAGE resolution decreased. Genomic DNA for RAPD analysis was prepared from adult flies, according to JowEtT (1986).

\section{Proteins Analysis with PAGE-SDS}

PAGE-SDS is a quick and sensitive method that separates a mixture of proteins according to their size and can be used for analyzing the protein variability between species.

Before separation, protein samples were submitted to stacking in $4 \%$ polyacrylamide gel, while a $12 \%$ polyacrylamide gel was used for separation. Coomassie stain was used for post-electrophoresis visualization and identification of protein bands.

\section{Genomic DNA Analysis through RAPD}

RAPD is a variation of the Polymerase Chain Reaction (PCR) and is very useful for detecting anonymous molecular markers dispersed on the genome. It is also very efficient in identifying polymorphisms.
The primers used in this study were decanucleotides constructed by the Nucleic Acid - Protein Service Unit of the University of British Columbia, Vancouver, Canada. They were P64 (5'GAG GGC GGG A3'), P71 (5'GAG GGC GAG G3'), P82 (5'GGG CCC GAC G3') and P91 (5'GGG TGG TTG C3'). Each amplification was carried out on $25 \mathrm{ml}$ samples, that contained: $2.5 \mathrm{ml}$ of $10 \mathrm{X} \mathrm{MgCl} 2$ free Reaction Buffer (Gibco/BRL), $2.5 \mathrm{mM}$ $\mathrm{MgCl} 2,200 \mathrm{nM}$ of each deoxinucleotide, $400 \mathrm{nM}$ of primer, 1.25 units of $\mathrm{Taq}$ polymerase (Gibco/BRL) and $100 \mathrm{ng}$ of genomic DNA. Amplification conditions were 45 s at $94^{\circ} \mathrm{C}, 45$ s at $37^{\circ} \mathrm{C}$ and $1 \mathrm{~min}$ at $72^{\circ} \mathrm{C}$, for 35 cycles. In the first cycle, there was a 5 mins denaturation period and in the last cycle there was a 7 mins elongation period. Amplification products were visualized in $7 \%$ polyacrylamide gels stained with silver nitrate.

\section{Morphological Analysis}

The continuous morphological characters given by VILELA $\&$ BäCHLI (1990) were used to construct a morphology matrix for each of the species (Table I).

\section{Data Analysis}

PAGE and RAPD analyses resulted in presence-absence data, which allowed manual binary analysis by comparison of the results obtained for the different species. To produce the final phylogenetic results, the data obtained by these comparisons was used to construct a matrix which was analyzed by the Penny program using Wagner's parsimony for PAGE data and by the Dollop program using the Dollo parsimony for RAPD data, both these programs belonging to the PHYLIP (FELSENSTEIN 1995) suite of programs.

Continuous characters were analyzed using the Contrast program, also from the PHYLIP suite of programs.

\section{RESULTS}

Analysis of the PAGE-SDS data resulted in the identification of 41 bands, most of which were evident and repetitive on the five replicated gels considered. This allowed calculation of the Jaccard Index (SJ), which estimates the genetic similarity between two species. In Table II it can be seen that the most similar species are $D$. griseolineata, $D$. maculifrons and $D$. ornatifrons, but it was not possible to establish the exact relationships between these species. What does become evident in these results is that of the four taxa examined, the protein profile of D. subbadia is the most different. Analysis of this data with the Penny program resulted in more than 28,000 phylogenetic trees, the most parsimonious of which (Fig. 1a) shows D. subbadia as the most distant species within the group. This tree also clustered $D$. griseolineata with $D$. ornatifrons, apparently resolving the problem of the relationships between these two species and $D$. maculifrons.

RAPD analysis resulted in 47 informative characters. Nevertheless, the results here obtained are incongruent with 
Table I. Some mean quantitative morphological characters of four Drosophila species of the guarani group as analyzed by VILELA \& BächLı (1990).

\begin{tabular}{l|c|c|c|c}
\hline Morphological Character & D. griseolineata & D. ornatifrons & D. maculifrons & D. subbadia \\
\hline Frontal index & 0.785 & 0.855 & 0.75 & 1,13 \\
Top to bottom width ratio & 1.21 & 1.185 & 1.23 & 1,17 \\
Length ratio of ant. to post. orbital & 0.67 & 0.695 & 0.73 & 1.0 \\
Length ratio of mid to ant. orbital & 0.4 & 0.46 & 0.345 & 0.42 \\
Cheek index & 8.0 & 9.5 & 8.0 & 12.0 \\
Eye index & 1.17 & 1.21 & 1.19 & 1.2 \\
Flagellomere length to width ratio & 1.8 & 1.665 & 1.8 & 1.5 \\
Vibrissal index & 0.765 & 0.95 & 0.885 & 1.0 \\
dc index & 0.67 & 0.67 & 0.72 & 0.63 \\
Scut index & 0.92 & 1.055 & 0.98 & 1.07 \\
Sterno index & 0.55 & 0.56 & 0.575 & 0.59 \\
Wing length to width ratio & 2.32 & 2.18 & 2.265 & 2.31 \\
C & 3.975 & 4.27 & 3.74 & 4.0 \\
Ac & 2.08 & 1.9 & 2.18 & 2.17 \\
4c & 0.755 & 0.57 & 0.705 & 0.62 \\
4v & 1.91 & 1.56 & 1.74 & 1.57 \\
5x & 1.25 & 1.14 & 1.2 & 1.43 \\
M & 0.575 & 0.445 & 0.48 & 0.48 \\
prox.X & 0.725 & 0.525 & 0.66 & 0.57 \\
Poc & 0.535 & 0.65 & 0.645 & 0.41 \\
Oc & 1.0 & 0.905 & 0.93 & 0.7 \\
Mid katepisternal & 0,72 & 0,77 & 0.68 & 0.75 \\
Ocellar triangle/frontal length ratio & 0,35 & 0,375 & 0.4 & 0.25 \\
Frontorbital plates/frontal length ratio & 0,65 & 0,7 & 0.675 & 0.5 \\
\hline
\end{tabular}

the previous one. The RAPD analysis SJ values are shown in Table II, where it can be seen that in this case D. subbadia presents a high similarity with $D$. ornatifrons, while the other taxa remain a little unordered with most of them showing a high degree of similarity. Using the Dollop program to resolve this question, the most parsimonious tree (Fig. 1b), as expected, clustered D. subbadia with $D$. ornatifrons, with $D$. griseolineata as the basal species.

With continuous morphological characters, analyzed by the Contrast program, the most parsimonious tree (Fig. 1c) presents a clade consisting of D. ornatifrons and $D$. subbadia, with $D$. maculifrons and $D$. griseolineata remaining as basal species.

\section{DISCUSSION}

Although some divergent results were obtained, the analyses of RAPD and continuous morphological characters showed the clustering of $D$. subbadia with $D$. ornatifrons, and this result agrees with the traditional relationships within the guarani subgroup of the Drosophila guarani species group

Table II. PAGE-SDS and RAPD Jaccard Index $\left(\mathrm{S}_{\mathrm{J}}\right)$ results for pairs of Drosophila species of the guarani group.

\begin{tabular}{lcc}
\hline Drosophila species pair & $\begin{array}{c}\text { PAGE-SDS } \\
\text { Jaccard } \\
\text { Index }\left(\mathbf{S}_{\mathbf{J}}\right)\end{array}$ & $\begin{array}{c}\text { RAPD } \\
\text { Jaccard } \\
\text { Index }\left(\mathbf{S}_{\mathbf{J}}\right)\end{array}$ \\
\hline D. griseolineata $\times$ D. maculifrons & 0.86 & 0.235 \\
D. griseolineata $\times$ D. ornatifrons & 0.85 & 0.22 \\
D. griseolineata X D. subbadia & 0.625 & 0.10 \\
D. ornatifrons x D. maculifrons & 0.76 & 0.28 \\
D. ornatifrons $\times$ D. subbadia & 0.56 & 0.23 \\
D. maculifrons x D. subbadia & 0.76 & 0.19 \\
& & \\
\hline
\end{tabular}


D.melanoga

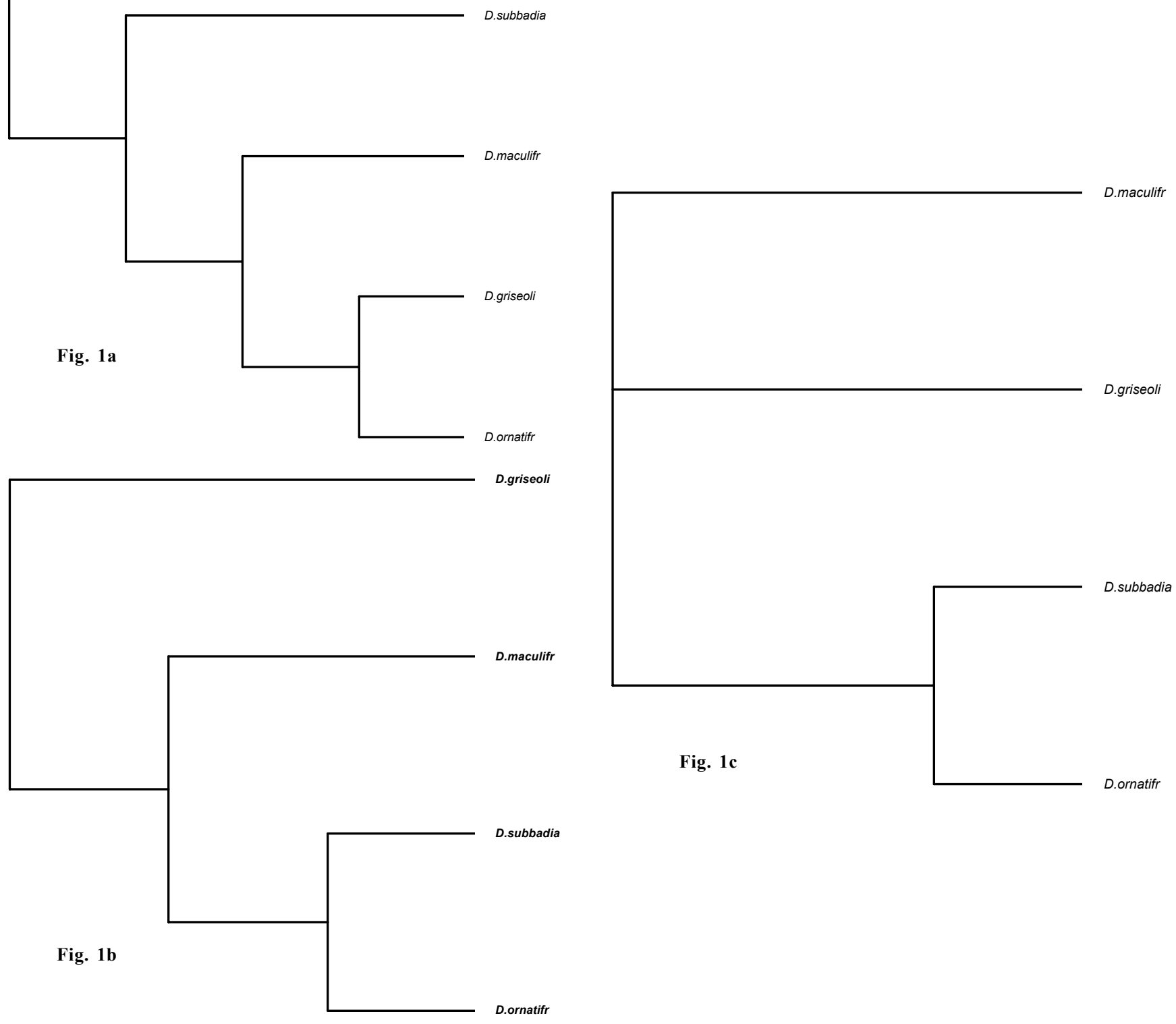

Fig. 1: Most parsimonious trees for four Drosophila species of the guarani group: a) As found by the Penny Program through the data obtained by PAGE-SDS analysis. In this case, Drosophila melanogaster was used as the outgroup species; b) As found by the Dollop Program through the data obtained by RAPD analysis; c) As found by the Contrast Program through the analysis of the continuou morphological character described by VILELA \& BäCHLI (1990).

(VAL et al. 1981). The data provided by PAGE-SDS show that the protein profile of the D. subbadia strain utilized in this study is the most different of the Drosophila species here analyzed. This result may be explained by the fact that the $D$. subbadia strain came from Mexico while the other strains are brazilian. So, local differences on selection pressure are the probable responsable for this incongruence.

Another important point is that none of the analyses were able to divide the $D$. guarani group into two subgroups. While $D$. subbadia and D. ornatifrons seem to form a monophyletic clade, the other two species did not cluster in any of the three trees. Nevertheless, the PAGE-SDS and RAPD SJ indicate that $D$. maculifrons and D. griseolineata present a high degree of similarity. It seems that to establish the relationship between these two species it will be necessary to include more species in any further study. Since it appears that the D. guarani 
species group is not monophyletic at all, perhaps the inclusion of D. tripunctata species group would allow to clarify this question. It may also be necessary to use other methods to obtain more information about the real evolutionary trends of this group.

Acknowledgements. We are grateful to Dra. Vera Lucia Gaiesky, for advice and suggestions, and to Dr. Robert Thomas, for English revision. Research supported by FAPERGS and PET/CAPES.

\section{REFERENCES}

DeSAlle, R. 1992. The phylogenetic relationships of flies in the family Drosophilidae deduced from mtDNA sequences. Molecular Phylogenetics and Evoltion 1: 31-40.

Felsenstein, J. 1995. PHYLIP - Phylogenetic Inference Package, Version 3.5. Washington University. Distributed by the author.

Grimaldi, D. A. 1990. A phylogenetic, revised classification of the genera in the Drosophilidae (Diptera). Bulletim of the American Museum of Natural History 197: 1-37.

Jowett, T. 1986. Preparation of nucleic acids, in Drosophila: a practical approach. Oxford, IRL Press.

Kastritsis, C. D. 1969. The chromosomes of some species of the guarani group of Drosophila. Journal of Heredity 60: 50-57.

Kwiatowski, J. \& F. J. Ayala. 1999. Phylogeny of Drosophila and Related Genera: Conflict between Molecular and Anatomical Analyses. Molecular Phylogenetics and Evolution 13(2): 319-328.
Mallogolowkin, C. 1953. Sobre a Genitália dos Drosofilídeos. IV. A genitália masculina no subgênero Drosophila (Diptera, Drosophilidae). Revista Brasileira de Biologia 13: 245-264.

O'Grady, P. M. \& M. G. Kidwell. 2002. Phylogeny of the subgenus Sophophora (Diptera; Drosophilidae) based on combined analysis of nuclear and mitochondrial sequences. Molecular Phylogenetics and Evolution 22(3) : 442-453.

Throckmorton, L. H. 1962. The problem of phylogeny in the genus Drosophila. University of Texas Publication 6205: 207-343.

Throckmorton, L. H. 1975. The Phylogeny, Ecology and Geography of Drosophila. V. 3. Handbook of Genetics. New York, Plenum.

Val, F. C.; C. R. Vilela \& M. D. Marques. 1981. Drosophilidae of Neotropical Region. p. 123-168. In: M.AshBURNER; H. L. CARSON \& J. N. Thompson (Edit.). The Genetics and Biology of Drosophila. V. 3a. Orlando, Academic Press.

Vilela, C. R. \& G. BäChli. 1990. Taxonomic studies on Neotropical species of seven genera of Drosophilidae (Diptera). Mitteilungen der Schweizerischen Entomologischen Gesellschaft 63 (Suppl.) : 1-332.

Vilela, C. R.\& M. A Q. R. Pereira. 1985. Notes on two species of spotthoraxed Drosophila belonging to the guarani group (Diptera, Drosophilidae). Revista Brasileira de Entomologia 29(3/4): 435442 .

Vilela, C. R \& M. A. Q. R. Pereira. 1993. A case of misidentification on a Neotropical species of Drosophila (Diptera, Drosophilidae) belonging to the guarani group. Revista Brasileira de Entomologia 37(4): 819-820.

WALKER, J. M. 1986. SDS Polyacrylamide Gel Electrophoresis of Proteins: Determination of Protein Molecular Weighs and High-Resolution Silver Staining, p. 149-160. In: R. J. Slater (Ed.). Experiments in Molecular Biology. Clifton, New Jersey. 